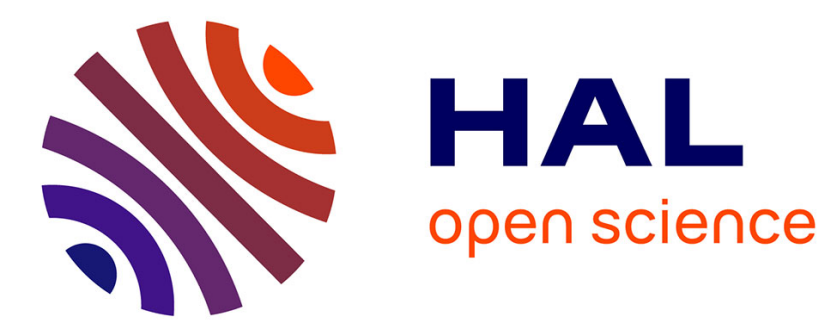

\title{
Correlation study on methoxylation pattern of flavonoids and their heme-targeted antiplasmodial activity
}

Sergio Ortiz, Pedro G Vásquez-Ocmín, Sandrine Cojean, Chouaha Bouzidi, Sylvie Michel, Bruno Figadere, Raphaël Grougnet, Sabrina Boutefnouchet, Alexandre Maciuk

\section{To cite this version:}

Sergio Ortiz, Pedro G Vásquez-Ocmín, Sandrine Cojean, Chouaha Bouzidi, Sylvie Michel, et al.. Correlation study on methoxylation pattern of flavonoids and their heme-targeted antiplasmodial activity. Bioorganic Chemistry, 2020, 104, 10.1016/j.bioorg.2020.104243 . hal-02990750

\section{HAL Id: hal-02990750 https://hal.science/hal-02990750}

Submitted on 17 Nov 2020

HAL is a multi-disciplinary open access archive for the deposit and dissemination of scientific research documents, whether they are published or not. The documents may come from teaching and research institutions in France or abroad, or from public or private research centers.
L'archive ouverte pluridisciplinaire HAL, est destinée au dépôt et à la diffusion de documents scientifiques de niveau recherche, publiés ou non, émanant des établissements d'enseignement et de recherche français ou étrangers, des laboratoires publics ou privés. 


\section{Correlation study on methoxylation pattern of flavonoids and their heme-targeted antiplasmodial activity}

Sergio Ortiz ${ }^{\mathrm{a} 1}$, Pedro G. Vásquez-Ocmín ${ }^{\mathrm{b} 1}$, Sandrine Cojean ${ }^{\mathrm{b}}$, Chouaha Bouzidi ${ }^{\mathrm{a}}$, Sylvie Michel $^{\mathrm{a}}$, Bruno Figadère ${ }^{\mathrm{b}}$, Raphaël Grougnet ${ }^{\mathrm{a}}$, Sabrina Boutefnouchet ${ }^{\mathrm{a} *}$, Alexandre Maciuk ${ }^{\mathrm{b} *}$.

${ }^{a}$ Université de Paris, Sorbonne Paris Cité, Equipe Produits Naturels, Analyses et Synthèse, CNRS UMR 8038 - CITCOM, Faculté de Pharmacie de Paris, 4 avenue de l'Observatoire Paris, France.

${ }^{\mathrm{b}}$ Université Paris-Saclay, CNRS, BioCIS, 92290, Châtenay-Malabry, France.

${ }^{1}$ these authors have equally contributed to the work.

* Corresponding authors.

E-mail address: alexandre.maciuk@universite-paris-saclay.fr (Alexandre Maciuk),

E-mail address: sabrina.boutefnouchet@parisdescartes.fr (Sabrina Boutefnouchet). 


\begin{abstract}
A library of 33 polymethoxylated flavones (PMF) was evaluated for heme-binding affinity by biomimetic MS assay and in vitro antiplasmodial activity on two strains of $P$. falciparum. Stability of heme adducts was discussed using the dissociation voltage at $50 \%\left(\mathrm{DV}_{50}\right)$. No correlation was observed between the methoxylation pattern and the antiparasitic activity, either for the 3D7 chloroquine-sensitive or for the W2 chloroquine-resistant $P$. falciparum strains. However, in each PMF family an increased $\mathrm{DV}_{50}$ was observed for the derivatives methoxylated in position 5. Measurement of intra-erythrocytic hemozoin formation of selected derivatives was performed and hemozoin concentration was inversely correlated with heme-binding affinity. Kaempferol showed no influence on hemozoin formation, reinforcing the hypothesis that this compound may exert in vitro antiplasmodial activity mostly through other pathways. Pentamethoxyquercetin has simultaneously demonstrated a significant biological activity and a strong interaction with heme, suggesting that inhibition of hemozoin formation is totally or partially responsible for its antiparasitic effect.
\end{abstract}

\title{
Keywords
}

Polymethoxyflavone, Plasmodium falciparum, Heme-binding, Hemozoin.

\section{Introduction}

Malaria is one of the major parasitic disease affecting humans [1]. In 2018, an estimated 228 million cases occurred worldwide and US\$ 2.7 billion from international efforts were invested for its control and eradication [2]. It is transmitted by the bite of female mosquitoes of Anopheles genus infected by Plasmodium spp. [3]. Malaria infection starts with a mosquito bite introducing Plasmodium sporozoites, which invade the host's liver cells. During the intraerythrocytic trophozoite stage of the life cycle, the parasite internalizes up to $80 \%$ of the host cell hemoglobin in a phagocytic organelle called cytostome [4]. The cytostome then transports hemoglobin into an acidic digestive vacuole $(\mathrm{pH}$ 5.2) where it is digested by proteolytic enzymes into small peptides used as source of amino acids for the parasite [5]. During this process, four molecules of heme (ferriprotoporphyrin IX), toxic to the parasite, are released for each hemoglobin unit digested. The main heme-detoxication pathway developed by Plasmodium spp. consists in the biocrystallization of heme into hemozoin, which is accumulated in the vacuole in an inert, solid form. This detoxication pathway has been the most attractive target in the search for new antimalarial drugs for decades [6-8]. It can be assessed in vitro by measuring crystallization of a solution of heme into the synthetic analog of hemozoin, referred to as $\beta$-hematin. 
Several antimalarial drugs including 4-aminoquinolines [9] and artemisinin [10] are able to form stable adducts with heme, thus impeding the detoxification process and contributing to the antiparasitic activity. We previously assessed the ability of polymethoxyflavones (PMFs) isolated from Pentzia monodiana to form adducts with heme in a mass spectrometry-based assay [11]. This first report of heme affinity for this class of compounds was intriguing as antimalarial activity was greatly variable, from low to significant $[11,12]$. In order to explore the structure-activity relationship within this chemical series and more precisely the influence of methoxylation/hydroxylation pattern, a library of 33 PMFs was generated and evaluated for heme-binding affinity by MS assay and in vitro antiplasmodial activity on two strains of $P$. falciparum (sensitive and resistant). MS-based collision induced dissociation allowed to establish the dissociation voltage at $50 \%\left(\mathrm{DV}_{50}\right)$ for each PMF-heme adduct. Calculation of physico-chemical parameters such as partition coefficient $(\log \mathrm{P})$ and topological polar surface area (tPSA) was carried out to provide indications about compounds lipophilicity. In addition, in order to correlate the heme-binding affinity with the in vitro antiplasmodial activity of PMFs, the intra-erythrocytic hemozoin formation of selected derivatives was measured.

\section{Results and discussion}

\subsection{PMFs library}

Sixteen PMFs were obtained by isolation from plant extracts (4 compounds from Pentzia monodiana, 8 compounds from Gardenia oudiepe) or as commercial standards (4 compounds). Then, methoxylation pattern was modified by two semisynthetic pathways with $\mathrm{MeI}$ or $\mathrm{Me}_{2} \mathrm{SO}_{4}$ as methyl donor in basic conditions (DBU or $\mathrm{K}_{2} \mathrm{CO}_{3}$ ), obtaining 17 derivatives [12,13]. The resulting library of 33 compounds, comprising 8 flavones (1-5, 23-25) and 25 flavonols (6-22, 26-33) can be clustered into 9 sub-families depending on their substitution in positions $3,5,6$, 7, 3', 4' and 5' by hydroxyl or methoxyl groups: derivatives of chrysin (1-2), apigenin (3-5), kaempferol (6-10), viscosine (11-14), quercetin (15-19), chrysoplenetin (20-22), eupatilin (2325), myricetin (26-29) and 5'-hydroxyquercetagetin (30-33) derivatives (Figure 1, Table 1).

\subsection{Physicochemical characteristics}

Calculation of partition coefficient $(\log \mathrm{P})$ and topological polar surface area (tPSA) was carried out to provide indications about lipophilicity of PMFs. Within each sub-family of derivatives, higher degree of methoxylation is positively correlated with increasing $\log \mathrm{P}$ and decreasing tPSA calculated values. This is due to the loss of the capacity of hydroxyl/phenol groups, once methoxylated, to form hydrogen bonds. This expected result is in accordance with previous reports [14]. 
However methoxylation of position 5 decreases the estimated $\log \mathrm{P}$. This drop of hydrophobicity for the methoxylated analogues is well known for flavonoids: the 5-OH is engaged in a strong intramolecular hydrogen bound with the carbonyl in position 4 [15]. This bound decreases the partial negative charge on the carbonyl oxygen atom and reduces the ability of the carbonyl group to form dipolar interactions with other polar molecules. If position 5 is bearing a methoxy group, the hydrogen binding ability of the carbonyl is restored and overrides the overall increase of hydrophobicity caused by the addition of a methoxy group, leading to a reduced LogP. This effect is obvious when comparing the following pairs of compounds: 9/10, 13/14, 21/22, 28/29 and 32/33. Apigenin derivative 5 does not conform to this hypothesis, without any explanation being found for that exception. An experimental measurement of the $\operatorname{LogP}$ should be made for this compounds to rule out a simulation software defect before concluding to a peculiar behavior of this compound. As a side observation, compound $\mathbf{1 8}$ shows that a phenol on position R3 can also establish an hydrogen bound with the carbonyl.

\subsection{Correlation between methoxylation degree and heme affinity}

A similar behavior is observed concerning the effect of methoxylation on the stability of hemeflavonoids adducts. Heme is hydrophobic, and hydrophobic interactions are involved in the formation of such adducts [16]. As methoxylation increases hydrophobicity of the flavonoids, it is expected to have an impact on the ability of the flavonoid to bind to heme. Such an effect is clearly observed for almost every family (derivatives of chrysin, apigenin, viscosine, quercetin, eupatilin, myricetin and 5'-hydroxyquercetagenin) with an increase of $\mathrm{DV}_{50}$ along with methoxylation degree. Methoxylation in position 5 is responsible for a slight decrease of cLogP, therefore it was expected to slightly decrease $\mathrm{DV}_{50}$. Instead, an unexpected, significant increase of $\mathrm{DV}_{50}$ by a factor 2 or more was systematically observed upon methoxylation in position 5 . Taking viscosine family as an example, $\mathrm{DV}_{50}$ values of derivatives 11-13 are in a range of 7.85 to $8.16 \mathrm{eV}$, whereas methoxylation increases $\mathrm{DV}_{50}$ up to 15.83 , an effect observed by a right shift of the sigmoid for compound $\mathbf{1 4}$ (Figure 2). These data suggest that hydrophobicity is not the only factor influencing binding, and that position 5 has a pivotal effect on heme binding. This hypothesis is currently being explored by docking experiments, based on a quantum model of free heme.

2.4 In vitro antiplasmodial activity of PMFs on 3D7 chloroquine-sensitive and W2 chloroquineresistant strains

Regarding in vitro antiplasmodial activity on $P$. falciparum, no correlation between methoxylation pattern and antiparasitic activity was observed, neither for the 3D7 chloroquinesensitive strain nor for the W2 chloroquine-resistant strain. However, some observations can be discussed within groups, considering $10 \mu \mathrm{M}$ as an efficacy cut-off value as recommended by 
OMS [17]. On 3D7 chloroquine-sensitive strain, all the quercetin derivatives tested (15 to 19) were active within a 3-9 $\mu \mathrm{M}$ range, regardless of their methoxylation degree. Within their own families, kaempferol $6\left(\mathrm{IC}_{50}=3.78 \mu \mathrm{M}\right)$, viscosine $11\left(\mathrm{IC}_{50}=6.06 \mu \mathrm{M}\right)$ and eupatilin $\left(\mathrm{IC}_{50}=\right.$ $29.31 \mu \mathrm{M}$ ) were the least methoxylated but the most active derivatives, other derivatives being mostly inactive. In these series, methoxylation of any phenol or hydroxyl group leads to a loss of activity. Inversely, for apigenin, chrysoplenetin, myricetin and 5'-hydroxyquercetagetin subfamilies, methoxylation would in some cases increase activity $(\mathbf{4}, \mathbf{2 2}, \mathbf{2 8}, \mathbf{3 2})$. Compounds from chrysin, eupatilin and myricetin sub-families were mostly inactive.

On W2 chloroquine-resistant strain, activities were for most compounds following the same pattern as on $3 \mathrm{D} 7$, with a slight decrease of $\mathrm{IC}_{50}$. This is well illustrated by the apigenin, viscosine, quercetin and 5'-hydroxyquercetagenin families. In some families, an increase of

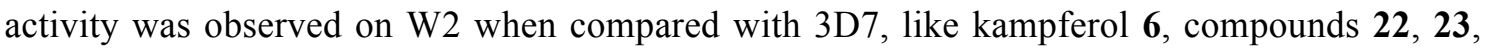
25 and 28. As with 3D7 results, no structure-activity relationships could be drawn, as within each family some derivatives showing either low or high degree of methoxylation were active. Kaempferol can be highlighted as one of the most active compound on both strains, and compounds 11, 15, 19, 22 and 32 were also active against both chloroquine-sensitive and resistant strains, without any obvious influence of the methoxylation degree or pattern.

Unfortunately, these data altogether do not allow to draw any predictive correlation between $\mathrm{DV}_{50}$ values and antiplasmodial activity. The most striking example is kaempferol $\mathbf{6}$, showing good antiparasitic activity but no binding at all to heme in the MS assay. These results highlight that affinity of PMFs for heme cannot be predictive of an antiplasmodial activity and that other mechanisms and targets may be implied in this effect. This hypothesis can be supported by the fact that flavonoids are known to be multi-target compounds, especially on protozoal organisms [18].

\subsection{In vitro hemozoin formation}

Hemozoin crystallization is not mediated by any enzyme, therefore an antiplasmodial mode of action based on its disruption cannot trigger resistance per se. Resistance against molecules showing this mode of action is mediated by modification of transport and efflux through the parasite membranes $[19,20]$.

To further decipher the biological impact of the observed heme-binding affinity in the MS assay, hemozoin was quantified after in vitro incubation of parasites in erythrocytes infected by the chloroquine-sensitive 3D7 strain together with 3 PMFs: kaempferol $\mathbf{6}$, active against 3D7 and $\mathrm{W} 2$ strains but not forming adduct with heme; tetramethoxykaempferol 10, inactive against 3D7 but forming very stable heme-adduct $\left(\mathrm{DV}_{50}=15.77 \mathrm{eV}\right)$; and pentamethoxyquercetin 19, 
with low $\mathrm{IC}_{50}$ against $3 \mathrm{D} 7(3.96 \mu \mathrm{M})$ and $\mathrm{W} 2(9.51 \mu \mathrm{M})$ strains and strongly binding to heme $\left(\mathrm{DV}_{50}=15.89 \mathrm{eV}\right)($ Figure 3).

In accordance with the results of the biomimetic MS binding assay, kaempferol $\mathbf{6}$ showed no influence in the quantity of hemozoin formation, reinforcing the hypothesis that this compound may exert its in vitro antiplasmodial activity mostly through other pathways. Indeed, kaempferol $\mathbf{6}$ and quercetin $\mathbf{1 5}$ are known to be inhibitors of FabG, FabZ and FabI enzymes, involved in type II fatty acid biosynthesis (FAS-II) of P. falciparum, essential to the life cycle of the parasites [21]. In addition, PMFs from kaempferol sub-family are reported as inhibitors of human serine-threonine kinase and thioredoxin reductase, which show high homology with their plasmodial equivalents, fundamental for parasite growth and survival [22-24].

Tetramethoxykaempferol $\mathbf{1 0}$ is able to form stable adduct in the MS assay but does not modify the in vitro hemozoin formation in 3D7 strain. Along with the absence of antiplasmodial activity, these data suggest that this compound may not reach its target in vitro. Explanations for such a biological inefficacy can be active efflux, rapid metabolization, poor solubility, poor membrane-crossing ability or binding to other non-vital targets. Some PMFs such as tangeretin and wogonin have been previously reported to show poor membrane permeability in several in vitro assays on biological membrane models [25]. These properties could hamper the penetration of methoxyflavonoids first into the erythrocyte, then through the parasite membrane. This suggests that some compounds may never reach the parasite vacuole, where hemozoin formation takes place. Noteworthy, absence of antiplasmodial activity is observed for almost all of the 5-methoxy derivatives $(5,10,14,29,33)$ and in a lower extent for the 5-hydroxy derivatives 20, 21 and 25. Methoxylation in R5 also systematically resulted in absence of cytotoxicity. It can therefore be interpreted as a pattern favoring a poor biological relevance.

Yet compound 19 is an exception to this hypothesis. Pentamethoxyquercetin $19\left(\mathrm{IC}_{50}=3.96 \mu \mathrm{M}\right.$ and $9.51 \mu \mathrm{M}$ on $3 \mathrm{D} 7$ and $\mathrm{W} 2$ strain, respectively and $\mathrm{DV}_{50}=15.89 \mathrm{eV}$ ) decreased hemozoin formation of $44 \%$ after $14 \mathrm{~h}$ of incubation. A similar effect was observed for chloroquine ( $\mathrm{DV}_{50}$ $=15.86 \mathrm{eV}$ ), which reduced hemozoin formation by $63 \%$. This result allows to correlate the heme-binding ability exerted by this compound in the MS assay with the antiplasmodial effect. In agreement with the $\mathrm{IC}_{50}$ values against both $P$. falciparum strains, we can hypothesize that one of the mechanisms of antiplasmodial activity of pentamethoxyquercetin $\mathbf{1 9}$ is the obstruction of the main detoxification mechanism of heme, by impeding hemozoin formation.

\subsection{Cytotoxic activity}

Eupatilin 23 was the strongest cytotoxic flavone when tested on HUVEC cells. Six other derivatives 12, 16, 17, 20, 21 and 26 have demonstrated an $\mathrm{IC}_{50}$ below $20 \mu \mathrm{M}$. They all possess 
a phenol group on position 5 and are methoxylated on R3 and R4', excepted for $\mathbf{2 3}$ and $\mathbf{1 6}$ which bear a hydrogen on R3 and a phenol group on R4', respectively.

\section{Conclusions}

Impairment of hemozoin formation is the main mechanism of action of major antimalarial drugs such as artemisinin and chloroquine. The thorough assessment of a series of PMFs for in vitro antiplasmodial activity, heme-binding affinity and physicochemical characteristics has provided valuable data about the influence of the substitution pattern on heme binding, principally methoxylation in position R5. However, no correlation between PMFs' heme affinity and antiplasmodial activity could be clearly drawn. Some flavonoids with significant biological activity, such as kaempferol, are already known to interfere with other parasitic targets. Pentamethoxyquercetin 19 has simultaneously demonstrated a significant biological activity and a strong interaction with heme, highlighting that inhibition of hemozoin formation is totally or partially responsible for its antiparasitic effect. In an intermediate case, a high affinity for heme associated to a weak biological activity may result from several physicochemical parameters affecting in vitro and in vivo biological activity (solubility of compounds, $\mathrm{pH}$ stability or membrane permeability). This highlights one of the limitations of the MS assay, which is a cellfree methodology, giving false positive cases. Further studies on this PMFs library regarding membrane permeability, molecular docking on heme and other biological and physicochemical proprieties are required to better understand the antiplasmodial activity of these compounds.

\section{Material and methods}

\subsection{Chemical and reagents}

Mass spectrometry analyses of compounds were performed on a Waters ZQ 2000 mass spectrometer (Saint-Quentin, France). Silica gel 60 25-40 $\mu \mathrm{m}$ (Macherey-Nagel GmbH \& Co, Düren, Germany) was used for column chromatography (CC). ${ }^{1} \mathrm{H}$ and ${ }^{13} \mathrm{C}$ NMR experiments were performed in deuterated chloroform on a Bruker AC $300 \mathrm{MHz}$ or a Bruker $400 \mathrm{MHz}$ spectrometer (Wissembourg, France) using Bruker pulse programs. All the reagents and solvents were purchased from Carlo Erba-SDS (Chaussée du Vexin, France). Cyclohexane and ethyl acetate were distilled before use. Deionized water was used for all experiments.

\subsection{Flavonoids library}

Flavonoids library is composed of either isolated, commercial or semi-synthetic derivatives. Compounds 7, 11, 12, 23, 26, 27, 30 and 31 were isolated from bud exudates of Gardenia 
oudiepe (Rubiaceae); flavones 20, 21, 24 and 25 were isolated from aerial parts of Pentzia monodiana (Asteraceae) [11,12]. Coumpounds 1, 3, 6 and 15 were purchased from Sarsyntex (Merignac, France) or Sigma Aldrich (St. Louis, MO, USA). Compounds 7-8, 13-14 and 32-33 were previously semisynthetized [12]. Compound $\mathbf{2}$ was obtained by methylation of $\mathbf{1}$; likewise, compound 4 and 5 were obtained from 3; 9 and 10 from 6; 16-19 from 15; 22 from 20 and 2829 from 27 (see section 4.5).

\subsection{Plant material}

G. oudiepe (Rubiaceae) buds were collected in October 2008 in Forêt Plate, North Province of New Caledonia. Voucher specimens (POU-0290 respectively) are kept at the Herbarium of the Botanical and Tropical Ecology Department of the IRD Center, Noumea, New Caledonia.

Aerial parts of P. monodiana (Asteraceae) were collected in the Algerian Southern Sahara, in Tassili Ahaggar National Park nearby the Tahat mountain (23 8"39.95", 5०43"46.28", alt.: $2019 \mathrm{~m}$ ), Wilaya of Tamanrasset, Algeria, in September 2013. The collection agreement was issued by the director of the Ahaggar National Park Office (OPNA), n 965/DPLBCVPC/MC/13 and 111/SDV/MC/13. Identification was done under supervision of M. Belghoul, head of Department of Study of Natural Resources from the Ahaggar National Park. A voucher specimen is stored at the Herbarium of the Department of Pharmacognosy, Paris Descartes University, France (voucher specimen MKOSB2013KDHPM).

\subsection{Extraction and isolation}

Fifty-five grams of $G$. oudiepe exudate were dissolved in $1 \mathrm{~L}$ of $\mathrm{CH}_{2} \mathrm{Cl}_{2}$ and paper-filtered in order to remove vegetal pieces. The residual gum was subjected to several steps of silica gel chromatographic separation using various mixtures of solvents of increasing polarity as eluent (cyclohexane $/ \mathrm{CH}_{2} \mathrm{Cl}_{2}, \mathrm{EtOAc} / \mathrm{CH}_{2} \mathrm{Cl}_{2}$ and $\mathrm{CH}_{2} \mathrm{Cl}_{2} / \mathrm{MeOH}$ ) to provide compounds 7, 11, 12, 23, 26, 27, 30 and 31.

Identification of isolated compounds was confirmed by NMR and MS analysis and by comparison with literature data [26,27].

\subsection{Semisynthesis of compounds 2, 4-5, 9-10, 16-19, 22, 28 and 29.}

Semisynthesis of compound 8 from 7; 13 and 14 from 12; 32 and 33 from 31 were previously reported, using dimethyl sulfate $\left(\mathrm{Me}_{2} \mathrm{SO}_{4}, 4\right.$ equiv.) and 1,8-diazobicyclo[5.4.0] undec-7-en (DBU, 2 equiv.) in dried acetone at room temperature [12]. Methylation of isolated compounds 20 and 27 to provide 22,28 and 29 and methylation of commercially available compounds $\mathbf{1 , 3 ,}$ 6 and 15 to provide compounds $2,4-5,9-10,16-19$, respectively, were performed by stirring the substrate with methyl iodide (MeI, 13.5 equiv.) and potassium carbonate $\left(\mathrm{K}_{2} \mathrm{CO}_{3}, 6.6\right.$ equiv.) in 
dried acetone at room temperature for $1 \mathrm{~h}$. The crude reaction mixtures were precipitated and washed with ice-cold water. The resulting residues were solubilized with EtOAc $(10 \mathrm{~mL})$ and treated with $1 \mathrm{~N} \mathrm{HCl}$ solution $(3 \mathrm{~mL})$. The final products were extracted with EtOAc $(3 \times 10 \mathrm{~mL})$ and the organic phases were washed with saturated $\mathrm{NaCl}$ solution and dried over $\mathrm{Na}_{2} \mathrm{SO}_{4}$. After filtration, and solvent evaporation, methylated compounds were purified by silica gel chromatography, using a mixture of $\mathrm{CH}_{2} \mathrm{Cl}_{2} / \mathrm{MeOH}(99.1 / 0.1$ to $95 / 5 \mathrm{v} / \mathrm{v})$ as eluent. Identification of resulting pure compounds was confirmed by comparison of ${ }^{1} \mathrm{H},{ }^{13} \mathrm{C}-\mathrm{NMR}$ and MS analysis with literature data.

Methylation of $50 \mathrm{mg}(0.20 \mathrm{mmol})$ of 5,7-dihydroxyflavone (chrysin, 1) afforded 2 (48.5 $\mathrm{mg}$, yield $92 \%)$ [28].

Methylation of $50 \mathrm{mg}(0.19 \mathrm{mmol})$ of 5,7,4'-trihydroxyflavone (apigenin, 3) gave 4 (31.6 $\mathrm{mg}$, $60 \%)$ and $5(8.3 \mathrm{mg}, 15 \%)$ with a ratio of $4 / 1$ [29].

Methylation of $100 \mathrm{mg}(0.35 \mathrm{mmol})$ of 5,7,3',4'-tetrahydroxyflavone (kaempferol, 6) gave 9 (71.1 $\mathrm{mg}, 62 \%)$ and $\mathbf{1 0}(14.3 \mathrm{mg}, 12 \%)$ with a ratio of 5/1 [30].

Methylation of $150 \mathrm{mg}(0.5 \mathrm{mmol})$ of 3,5,7,3',4'-pentahydroxyflavone (quercetin, 15) gave $\mathbf{1 6}$ (15.6 mg, $10 \%), 17$ (15.6 mg, $9.5 \%), 18$ (97.8 mg, $55 \%)$ and $\mathbf{1 9}(17.0,9.2 \%)$ with a ratio of $1 / 1 / 6 / 1[31-33]$.

Methylation of $6 \mathrm{mg}(0.017 \mathrm{mmol})$ of $\mathbf{2 0}$ gave $22(5.5 \mathrm{mg}, 85 \%)$ [34].

Methylation of $12 \mathrm{mg}(0.032 \mathrm{mmol})$ of 27 gave $\mathbf{2 8}(7.5 \mathrm{mg}, 61 \%)$ and $\mathbf{2 9}(3.9 \mathrm{mg}, 28 \%)$ with a ratio of $2 / 1[35]$.

\subsection{Biomimetic heme-binding assay by $M S$}

Hemin (iron-containing porphyrin with chlorine counterion) and compounds were dissolved in DMSO at $5 \mathrm{mM}$. Citric buffer saturated octanol (CBSO) [36] was prepared by mixing $5 \mathrm{~mL}$ of citric acid $50 \mathrm{mM} \mathrm{pH} 5.2$ and $15 \mathrm{~mL}$ of n-octanol (anhydrous, $\geq 99 \%$ ) and letting it to settle at $23{ }^{\circ} \mathrm{C}$ for $30 \mathrm{~min}$. Upper phase of CBSO was used. An auto sampler (G1367E 1260 Hip ALS, Agilent Technologies, Les Ulis, France) was used to realize the automatic mixing in 384 wellplates of: test compound $5 \mu \mathrm{L}+$ heme $5 \mu \mathrm{L}+$ tween $20(10 \mu \mathrm{M}$ in water $) 5 \mu \mathrm{L}+$ CBSO $85 \mu \mathrm{L}$. Five microliters of the sample were injected in infusion mode (direct injection) in a 6530 Accurate-Mass QToF LC/MS instrument (Agilent Technologies) with the following settings: positive ESI mode, $2 \mathrm{GHz}$ acquisition rate. Ionization source conditions were: drying gas temperature $325{ }^{\circ} \mathrm{C}$, drying gas flow rate $11 \mathrm{~L} / \mathrm{min}$, nebulizer $35 \mathrm{psig}$, fragmentor $175 \mathrm{~V}$, skimmer $65 \mathrm{~V}$. Range of $m / z$ was 200-1700. In the positive-ion mode, purine $\mathrm{C}_{5} \mathrm{H}_{4} \mathrm{~N}_{4}[\mathrm{M}+\mathrm{H}]^{+}$ ion $(\mathrm{m} / \mathrm{z} 121.050873)$ and the hexakis $(1 \mathrm{H}, 1 \mathrm{H}, 3 \mathrm{H}$-tetrafluoropropoxy)-phosphazene 
$\mathrm{C}_{18} \mathrm{H}_{18} \mathrm{~F}_{24} \mathrm{~N}_{3} \mathrm{O}_{6} \mathrm{P}_{3}[\mathrm{M}+\mathrm{H}]^{+}$ion $(\mathrm{m} / z 922.009$ 798) were used as internal lock masses. Full scans were acquired at a resolution of $11000($ at $\mathrm{m} / \mathrm{z}$ 922). On the same spectrum (spectral windows) appears heme at $\mathrm{m} / \mathrm{z}$ 616.16; adducts at $\mathrm{m} / \mathrm{z} 616.16$ + mass of ligand and 2heme + mass of ligand; heme + DMSO at $\mathrm{m} / z$ 694.19; heme dimer at $\mathrm{m} / \mathrm{z} 1231.32[2 \text { heme }-\mathrm{H}]^{+}$. Chloroquine 5 $\mathrm{mM}$ in water (chloroquine diphosphate, Sigma-Aldrich) was used as positive control [37].

\subsection{Collision induced dissociation of non-covalent adducts}

Dissociation voltage at $50 \%\left(\mathrm{DV}_{50}\right)$ was determined by applying increasing collision energy from 0 to $32 \mathrm{eV}$. MSMS targeted mode, with isolation width of $\sim 1.3 \mathrm{~m} / \mathrm{z}$ and flow injection analysis mode (FIA) were used. MSMS source parameters were the same as described above. Results were plotted and a sigmoidal regression curve was calculated using GraphPad Prism software. $\mathrm{DV}_{50}$ is the collision energy dissociating $50 \%$ of the adduct $[37,38]$.

\subsection{Culture of Plasmodium falciparum}

The chloroquine-sensitive 3D7 and chloroquine-resistant W2 P. falciparum strains were obtained from Malaria French National Reference Center (CNR Paludisme, Hôpital Bichat Claude Bernard, Paris). The strains were maintained in $\mathrm{O}+$ human erythrocytes in albuminsupplemented RPMI medium under continuous culture using the candle-jar method. The parasites were synchronized to the ring stage by repeated sorbitol treatment.

\subsection{In vitro antiplasmodial activity}

A $2.5 \%(\mathrm{~V} / \mathrm{V})$ erythrocytes suspension with $1 \%$ parasitemia was incubated with the compounds. Compound concentrations obtained by serial dilution ranged between $48.5 \mathrm{nM}$ and $1 \mu \mathrm{M}$. Assays were made in duplicates. After $44 \mathrm{~h}$ of incubation at $37{ }^{\circ} \mathrm{C}$, plates were subjected to 3 freeze-thaw cycles to achieve complete hemolysis. The parasite lysis suspension was diluted by 1:5 in lysis buffer. Monitoring of in vitro susceptibility uses the concentration that inhibits $50 \%$ of the parasite growth $\left(\mathrm{IC}_{50}\right)$. Parasite growth was determined by using SYBR ${ }^{\circledR}$ Green $\mathrm{I}$, a dye showing strong fluorescence enhancement upon contact with parasite DNA. Incorporation of $\mathrm{SYBR}^{\circledR}$ Green I (Applied Biosystems, Strasbourg, France) in parasite DNA was measured using the Mastercycler epRealplex (Eppendorf, France) according to the following program to increase the SYBR ${ }^{\circledR}$ Green I incorporation: $90{ }^{\circ} \mathrm{C}(1 \mathrm{~min})$, decrease in temperature from $90{ }^{\circ} \mathrm{C}$ to $10{ }^{\circ} \mathrm{C}$ (during $5 \mathrm{~min}$ ), followed by fluorescence reading. Untreated infected and uninfected erythrocytes were used as controls and chloroquine diphosphate (Sigma, France) as reference drug $[39,40] . \mathrm{IC}_{50}$ were calculated by IC-estimator online software (http://www.antimalarialicestimator.net).

\subsection{Cytotoxic activity}


For determination of cytotoxicity, human umbilical vein endothelial cells (HUVECs) were cultured in Dulbecco's Modified Eagle medium/nutrient mixture F-12 (DMEM-F12) medium in the presence of $10 \%$ fetal bovine serum (FBS) plus $1 \%$ streptomycin and incubated in $5 \% \mathrm{CO}_{2}$ at $37{ }^{\circ} \mathrm{C}$. Cytotoxicity of compounds (starting concentration of $10 \mathrm{mM}$ ) was evaluated using MTT (3-(4,5-dimethylthiazol-2-yl)-2,5-diphenyltetrazolium bromide) colorimetric method [40]. HUVEC cells were seeded in a 96-well plate at 15,000 cells per well and incubated for $24 \mathrm{~h}$ until cells reached $>80 \%$ confluence. After discarding the old medium, the cells were incubated in the medium containing test compound at eight concentrations ranging from 0.78 to $50 \mu \mathrm{M}$. After $24 \mathrm{~h}$ incubation, $20 \mu \mathrm{L}$ of MTT $(5 \mathrm{mg} / \mathrm{mL})$ were added to each well and cells were incubated for another $3 \mathrm{~h}$. Finally, the culture medium containing MTT solution was removed and $100 \mu \mathrm{L}$ DMSO were added to dissolve formazan crystals. Absorbance was read with an Eppendorf plate reader at $546 \mathrm{~nm}$. $\mathrm{IC}_{50}$, defined as compound concentration that reduces the number of viable cells by $50 \%$, was calculated using GraphPad Prism Software (Version 5.0, San Diego, CA, USA) [39].

\subsection{ADMET Prediction}

FAF-Drugs4 [42] and ChemSketch (ACD/Labs Products) software were used to screen the flavonoids library in order to predict their ADMET proprieties. For FAF-Drugs 4 online service, the input structures (as a previously generated SDF files) were formatted according to FAFDrugs4's requirements using Bank-Formatter. XLOGP3 was chosen as the clogP computation program to estimate the lipophilicity and the derived ADMET descriptors. For ChemSketch software, the input files were previously generated as SK2 files and prediction of clogP were estimated for all compounds [41].

\subsection{Hemozoin in vitro formation}

Hemozoin in vitro formation was evaluated by Heller and Roepe methodology [42] with slight modifications. Briefly, $8 \mathrm{~mL}$ of synchronized plasmodial culture of 3D7 P. falciparum strain at $2.5 \%(\mathrm{v} / \mathrm{v})$ erythrocytes suspension with $3 \%$ of parasitemia were incubated with test compounds at $\mathrm{IC}_{90}$ concentration in duplicates and cultivated as previously described conditions. After 9,14 and $17 \mathrm{~h}$ of incubation, the suspension cultures were centrifuged, and parasite were lyzed with $0.1 \%$ saponin solution $(w / v)$. Samples were then washed four times with ice-cold PBS buffer to yield purified parasites pellets. Then, pellets were washed once with $150 \mu \mathrm{L}$ of PBS, $50 \mu \mathrm{L}$ of $\mathrm{H}_{2} \mathrm{O}$ and $50 \mu \mathrm{L}$ of 1 M HEPES to remove any final traces of hemoglobin. Four hundred $\mu \mathrm{L}$ of $4 \%$ SDS in $0.1 \mathrm{M} \mathrm{NaHCO}_{3}$ were added to the pellet, and the mixture was shaken and incubated at $37^{\circ} \mathrm{C}$ for $2.5 \mathrm{~h}$ and then centrifuged at $1300 \mathrm{rpm}$. The pellet containing hemozoin was washed three times with bicarbonate buffer and finally 
dissolved in $500 \mu \mathrm{L}$ of $3 \mathrm{~N} \mathrm{NaOH}$ solution. One hundred microliters were placed into 96-well plate and UV absorption was read at $405 \mathrm{~nm}$.

Acknowledgments

The authors acknowledge Dr. Vincent Dumontet for collection of G. oudiepe exudates and the North Province of New Caledonia for facilitation of field investigations, Pr. Guy Lewin for fruitful discussions, Comisión Nacional de Investigación Científica y Tecnológica of Chile for $\mathrm{PhD}$ funding of Dr Sergio Ortiz, Consejo de Ciencia y Tecnología del Perú (CONCYTEC) for the PhD scholarship of Dr Pedro Vásquez-Ocmín.

\section{References}

[1] N.J. White, S. Pukrittayakamee, T.T. Hien, M.A. Faiz, O.A. Mokuolu, A.M. Dondorp, Malaria, The Lancet. 383 (2014) 723-735. https://doi.org/10.1016/S0140-6736(13)600240.

[2] World malaria report 2019, (n.d.). https://www.who.int/publications-detail/world-malariareport-2019 (accessed January 17, 2020).

[3] L.H. Miller, H.C. Ackerman, X.Z. Su, T.E. Wellems, Malaria biology and disease pathogenesis: Insights for new treatments, Nat. Med. 19 (2013) 156-167. https://doi.org/10.1038/nm.3073.

[4] D.E. Goldberg, A.F. Slater, R. Beavis, B. Chait, A. Cerami, G.B. Henderson, Hemoglobin degradation in the human malaria pathogen Plasmodium falciparum: a catabolic pathway initiated by a specific aspartic protease., The Journal of Experimental Medicine. 173 (1991) 961-9. https://doi.org/10.1084/jem.173.4.961.

[5] T.J. Egan, Haemozoin formation, Mol. Bioch. Parasitology. 157 (2008) 127-136. https://doi.org/10.1016/j.molbiopara.2007.11.005.

[6] A.P. Gorka, A. de Dios, P.D. Roepe, Quinoline Drug-Heme interactions and implications for antimalarial cytostatic versus cytocidal activities, J. Med. Chem. 56 (2013) 52315246. https://doi.org/10.1021/jm400282d.

[7] B.L. Tekwani, L.A. Walker, Targeting the hemozoin synthesis pathway for new antimalarial drug discovery: technologies for in vitro beta-hematin formation assay., Comb Chem High Throughput Screen. 8 (2005) 63-79. https://doi.org/10.2174/1386207053328101. 
[8] I. Weissbuch, L. Leiserowitz, Interplay between Malaria, crystalline hemozoin formation, and antimalarial drug action and design, Chem. Rev. 108 (2008) 4899-4914. https://doi.org/10.1021/cr078274t.

[9] K.Y. Fong, D.W. Wright, Hemozoin and antimalarial drug discovery, Future Med. Chemistry. 5 (2013) 1437-1450. https://doi.org/10.4155/fmc.13.113.

[10] J. Li, B. Zhou, Biological actions of Artemisinin: Insights from medicinal chemistry studies, Molecules. 15 (2010) 1378-97. https://doi.org/10.3390/molecules15031378.

[11] S. Ortiz, K. Dali-Yahia, P. Vasquez-Ocmin, R. Grougnet, P. Grellier, S. Michel, A. Maciuk, S. Boutefnouchet, Heme-binding activity of methoxyflavones from Pentzia monodiana Maire (Asteraceae), Fitoterapia. $118 \quad$ (2017) 1-5. https://doi.org/10.1016/j.fitote.2017.01.012.

[12] L.H. Mai, G.G. Chabot, P. Grellier, L. Quentin, V. Dumontet, C. Poulain, L.S. Espindola, S. Michel, H.T.B. Vo, B. Deguin, R. Grougnet, Antivascular and anti-parasite activities of natural and hemisynthetic flavonoids from New Caledonian Gardenia species (Rubiaceae), Europ. J. Med. Chem. $93 \quad$ (2015) 93-100. https://doi.org/10.1016/j.ejmech.2015.01.012.

[13] T.T. Dao, Y. Sook Chi, J. Kim, H.P. Kim, S. Kim, H. Park, Synthesis and PGE2 inhibitory activity of 5,7-Dihydroxyflavones and their O-Methylated flavone analogs, Arch. Pharm. Res. 26 (2003) 345-350. https://doi.org/10.1007/BF02976690.

[14] W.L. Whaley, J.-T. Tseng, J.D. Rummel, C.L. Wommack, Monohydroxyflavones: distribution coefficients and affinities for Reverse-Phase (C18) and immobilized artificial membrane (IAM) adsorbents, Nat. Prod. Commun. 2 (2007) 1934578X0700201005. https://doi.org/10.1177/1934578X0700201005.

[15] W.L. Whaley, J.D. Rummel, N. Kastrapeli, Interactions of Genistein and related isoflavones with lipid micelles, Langmuir. 22 (2006) 7175-7184. https://doi.org/10.1021/la0606502.

[16] K. Bachhawat, C.J. Thomas, N. Surolia, A. Surolia, Interaction of Chloroquine and its analogues with Heme: An isothermal titration calorimetric study, Biochem. Biophys. Res. Commun. 276 (2000) 1075-1079. https://doi.org/10.1006/bbrc.2000.3592.

[17] WHO, World malaria report 2017, World Heal, Luxembourg, 2017.

[18] É.B.V.S. Cavalcanti, V. de Paulo Emerenciano, L. Scotti, M.T. Scotti, Chapter 7 Flavonoids from Asteraceae as multitarget source of compounds against protozoal diseases, in: A. Speck-Planche (Ed.), Multi-Scale approaches in drug discovery, Elsevier, 2017: pp. 149-190. https://doi.org/10.1016/B978-0-08-101129-4.00007-2.

[19] R.E. Martin, R.V. Marchetti, A.I. Cowan, S.M. Howitt, S. Bröer, K. Kirk, Chloroquine transport via the malaria parasite's Chloroquine resistance transporter, Science. 325 (2009) 1680-1682. https://doi.org/10.1126/science.1175667. 
[20] T.E. Wellems, L.J. Panton, I.Y. Gluzman, V.E. do Rosario, R.W. Gwadz, A. WalkerJonah, D.J. Krogstad, Chloroquine resistance not linked to $\mathrm{mdr}$-like genes in a Plasmodium falciparum cross, Nature. $345 \quad$ (1990) 253-255. https://doi.org/10.1038/345253a0.

[21] D. Tasdemir, G. Lack, R. Brun, P. Rüedi, L. Scapozza, R. Perozzo, Inhibition of Plasmodium falciparum fatty acid biosynthesis: Evaluation of FabG, FabZ, and FabI as drug targets for flavonoids, J. Med. Chem. 49 (2006) 3345-3353. https://doi.org/10.1021/jm0600545.

[22] H. Masatoshi, I. Shigeo, T. Toshio, N. Kazuo, I. Masaaki, H. Hiroyoshi, Differential effects of flavonoids as inhibitors of tyrosine protein kinases and serine/threonine protein kinases, Biochem. Pharmacol. 37 (1988) 2987-2992. https://doi.org/10.1016/00062952(88)90286-9.

[23] J. Lu, L.V. Papp, J. Fang, S. Rodriguez-Nieto, B. Zhivotovsky, A. Holmgren, Inhibition of mammalian Thioredoxin reductase by some flavonoids: Implications for Myricetin and Quercetin anticancer activity, Cancer Res. $66 \quad$ (2006) 4410-4418. https://doi.org/10.1158/0008-5472.CAN-05-3310.

[24] Z. Krnajski, T.-W. Gilberger, R.D. Walter, A.F. Cowman, S. Müller, Thioredoxin reductase is essential for the survival of Plasmodium falciparum erythrocytic stages, J. Biol. Chem. 277 (2002) 25970-25975. https://doi.org/10.1074/jbc.M203539200.

[25] X.-J. Tian, X.-W. Yang, X. Yang, K. Wang, Studies of intestinal permeability of 36 flavonoids using Caco-2 cell monolayer model, Int. J. Pharm. 367 (2009) 58-64. https://doi.org/10.1016/j.ijpharm.2008.09.023.

[26] E. Ayanoglu, A. Ulubelen, W.D. Clark, G.K. Brown, R.R. Kerr, T.J. Mabry, Myricetin and quercetin methyl ethers from Haplopappus integerrimus var. Punctatus, Phytochemistry. 20 (1981) 1715-1717. https://doi.org/10.1016/S0031-9422(00)98561-3.

[27] C. Demetzos, D. Angelopoulou, A. Kolocouris, I. Daliani, T. Mavromoustakos, Structure elucidation, conformational analysis and thermal effects on membrane bilayers of an antimicrobial myricetin ether derivative, J. Heterocycl. Chem. 38 (2001) 703-710. https://doi.org/10.1002/jhet.5570380327.

[28] Z. Sipos, K. Kónya, Synthesis of benzopyran-fused flavone derivatives via microwaveassisted intramolecular C-H activation, Synthesis. $50 \quad$ (2018) 1610-1620. https://doi.org/10.1055/s-0036-1591773.

[29] K. Lu, J. Chu, H. Wang, X. Fu, D. Quan, H. Ding, Q. Yao, P. Yu, Regioselective iodination of flavonoids by N-iodosuccinimide under neutral conditions, Tetrahedron Lett. 54 (2013) 6345-6348. https://doi.org/10.1016/j.tetlet.2013.09.051. 
[30] K. Kato, M. Ninomiya, K. Tanaka, M. Koketsu, Effects of functional groups and sugar composition of Quercetin derivatives on their radical scavenging properties, J. Nat. Prod. 79 (2016) 1808-1814. https://doi.org/10.1021/acs.jnatprod.6b00274.

[31] Z. Yuan, G. Luan, Z. Wang, X. Hao, J. Li, Y. Suo, G. Li, H. Wang, Flavonoids from Potentilla parvifolia Fisch. and their neuroprotective effects in human neuroblastoma SHSY5Y cells in vitro, Chem. Biodiver. $14 \quad$ (2017) e1600487. https://doi.org/10.1002/cbdv.201600487.

[32] M. Cormier, F. Ghouili, P. Roumaud, L.J. Martin, M. Touaibia, Influence of flavonols and quercetin derivative compounds on MA-10 Leydig cells steroidogenic genes expressions, Toxicol. in Vitro. 44 (2017) 111-121. https://doi.org/10.1016/j.tiv.2017.06.027.

[33] M.A. Arai, Y. Kofuji, Y. Tanaka, N. Yanase, K. Yamaku, R.G. Fuentes, U.K. Karmakar, M. Ishibashi, Synthesis of rocaglamide derivatives and evaluation of their Wnt signal inhibitory activities, Org. Biomol. Chem. $14 \quad$ (2016) 3061-3068. https://doi.org/10.1039/C5OB02537K.

[34] S. Li, C.-Y. Lo, C.-T. Ho, Hydroxylated polymethoxyflavones and methylated flavonoids in sweet orange (Citrus sinensis) Peel, J. Agric. Food Chem. 54 (2006) 4176-4185. https://doi.org/10.1021/jf060234n.

[35] M.S. Butler, P.C. Healy, P.I. Forster, G.P. Guymer, R.J. Quinn, 5,6,7,3', 4', $^{\prime}$ ' $^{\prime}$ Hexamethoxyflavone from the Australian plant Eremophila debilis (Myoporaceae), Fitoterapia. 126 (2018) 90-92. https://doi.org/10.1016/j.fitote.2017.07.014.

[36] K.N. Olafson, M.A. Ketchum, J.D. Rimer, P.G. Vekilov, Mechanisms of hematin crystallization and inhibition by the antimalarial drug chloroquine, PNAS. 112 (2015) 4946-4951. https://doi.org/10.1073/pnas.1501023112.

[37] P. Vásquez-Ocmín, J.-F. Gallard, A.-C.V. Baelen, K. Leblanc, S. Cojean, E. Mouray, P. Grellier, C. Amasifuén, G. Bernadat, L. Evanno, B. Figadère, A. Maciuk, Antiplasmodial biodereplication based on highly efficient methods, (2020). https://doi.org/10.26434/chemrxiv.11828802.v1.

[38] K. Muñoz-Durango, A. Maciuk, A. Harfouche, S. Torijano-Gutiérrez, J.-C. Jullian, J. Quintin, K. Spelman, E. Mouray, P. Grellier, B. Figadère, Detection, characterization, and screening of heme-binding molecules by mass spectrometry for malaria drug discovery, Anal. Chem. 84 (2012) 3324-3329. https://doi.org/10.1021/ac300065t.

[39] P. Vásquez-Ocmín, S. Cojean, E. Rengifo, S. Suyyagh-Albouz, C.A. Amasifuen Guerra, S. Pomel, B. Cabanillas, K. Mejía, P.M. Loiseau, B. Figadère, A. Maciuk, Antiprotozoal activity of medicinal plants used by Iquitos-Nauta road communities in Loreto (Peru), J. Ethnopharmacol. 210 (2018) 372-385. https://doi.org/10.1016/j.jep.2017.08.039. 
[40] T. Mosmann, Rapid colorimetric assay for cellular growth and survival: Application to proliferation and cytotoxicity assays, J. Immunol. Methods. 65 (1983) 55-63. https://doi.org/10.1016/0022-1759(83)90303-4.

[41] D. Lagorce, L. Bouslama, J. Becot, M.A. Miteva, B.O. Villoutreix, FAF-Drugs4: free ADME-tox filtering computations for chemical biology and early stages drug discovery, Bioinformatics. 33 (2017) 3658-3660. https://doi.org/10.1093/bioinformatics/btx491.

[42] L.E. Heller, P.D. Roepe, Quantification of Free Ferriprotoporphyrin IX Heme and Hemozoin for Artemisinin Sensitive versus Delayed Clearance Phenotype Plasmodium falciparum Malarial Parasites, Biochemistry. $57 \quad$ (2018) 6927-6934. https://doi.org/10.1021/acs.biochem.8b00959. 